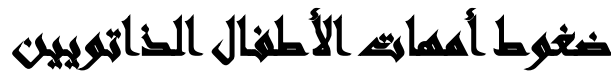

\section{[?]}

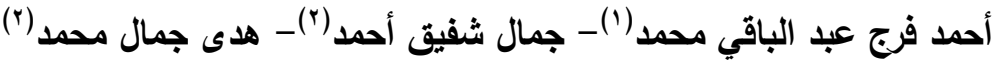

() مؤسسة الدكتورة سعاد كفافي، جامعة مصر للعلوم والتكنولوجيا r) كلية الدراسات العليا

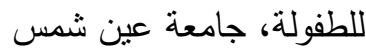

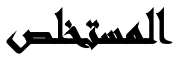

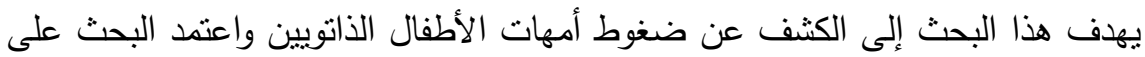

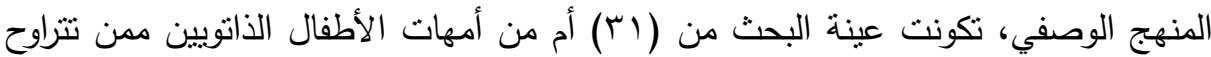

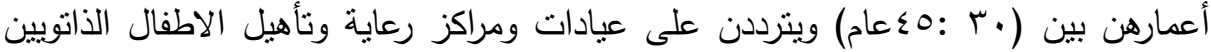

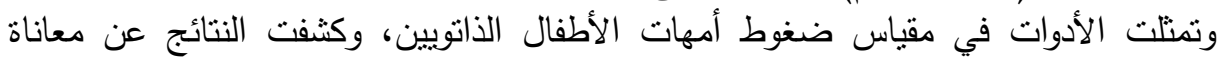

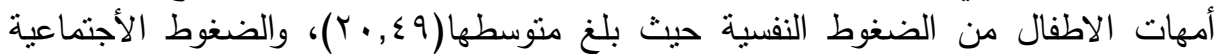

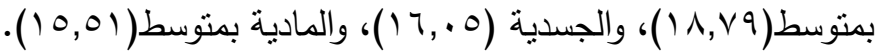

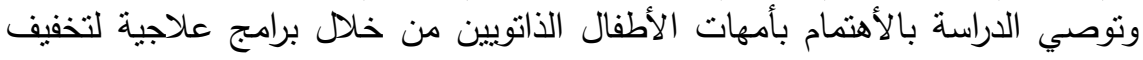
حدة الضغوط النفسية والاجتماعية والمادية والفسيولوجية.

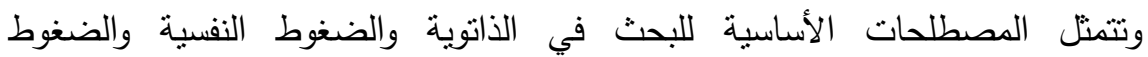
الاجتماعية والضغوط الفسيولوجية والضغوط المادية.

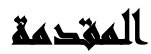

يواجه الفرد فى حياته العديد من المواقف الضاغطة والتى تتضمن خبرات غير مرغوب فيها، وأحداث تتطوى على الكثير من مصادر القلق وعوامل الخطر والتهديد فى كافة هئة المجالات الحياتية، وقد انعكست آثار تلك المواقف الضاغطة على معظم جوانب الثخصية،

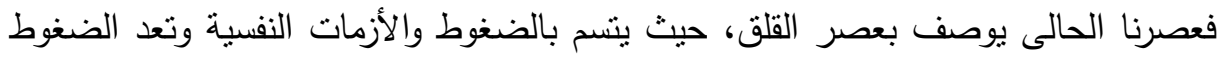
فى حد ذاتها إحدى الظواهر الإنسانية التى يتعرض لها الفرد طول حياته، فتعقد ظروف الحياة وحدوث تغيرات اجتماعية واقتصادية من الصعب ملاحقتها قد أصابت النسق القيهى لهنى بكافة 
أثكاله وأنواعه بقدر كبير من الوهن، حيث ظهرت أنماط من السلوك السلبى الناتج عن اضطراب العلاقات الإنسانية ونقص مهارات الفرد للتعامل مع المواقف الضاغطة. وتتثير الضغوط النفسية إلى المواقف الاجتماعية والمهنية السالبة والموجبة التى تسبب للفرد

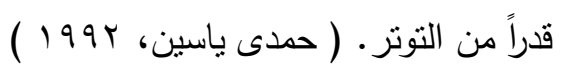
فهى العوامل الخارجية التى تحدث للفرد إحساساً بالتوتر وعندما تزداد شدة هذه الضغن الضغوط

قد يفقد الفرد قدرته على الاتزان ويغير من نمط سلوكه. ( سامى عبد القوى ، 1990 )

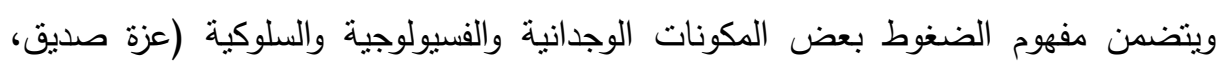
$\cdot(r \cdot r$ وما لا يدعو مجالا للثك أن المرأة بوجه عام والمصرية بوجه خاص تعد أكثر فئات

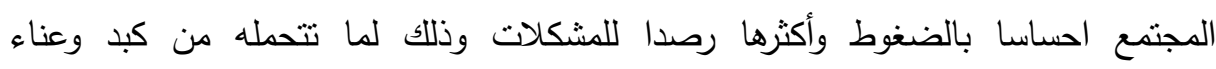

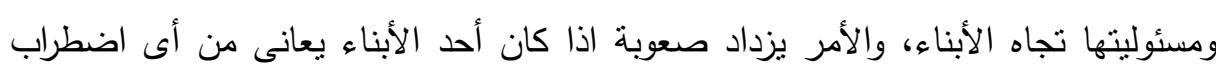

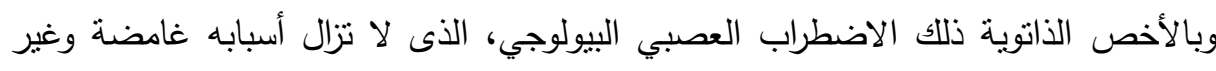

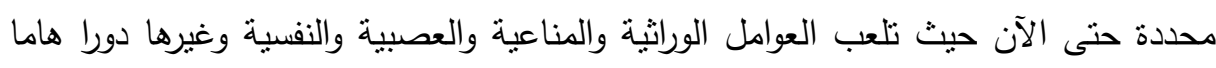

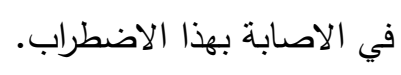

تعرف الذاتوية بأنها اضطراب نفسي عصبي ذو بداية مبكرة ويشير إلي اضطراب في الارتقاء الاجتماعي والمعرفي ويتسم هذا الاضطراب بمستوي محدد من الذكاء ( Volkmar

. 1991،and Cohen

كما نم تعريفها بأنها اضطراب بيولوجي عصبي يحدث اختلال وظيفي في التواصل

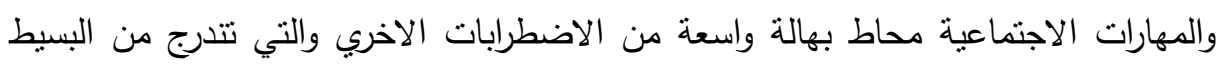

$$
\text { إلي الثديد)(Autism Info 2004) }
$$

وتعرف أيضا بأنها خلل في النمو العصبي البيولوجي، وينسم هذا الخلل بطول الأمد أي

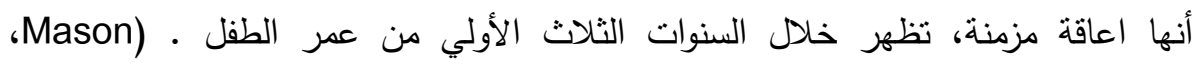
.(2005

وانطلاقا مما سبق تم اجراء هذا البحث بغرض الكثف عن ضـوط أمهات الأطفال الذاتوبين. 


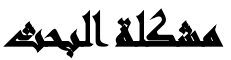

يعتبر اضطراب الذانوية من أكثر الاضطرابات النمائية شيوعاً بين الأطفال في عصرنا

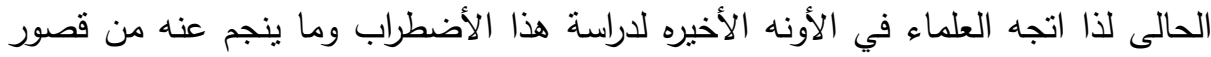

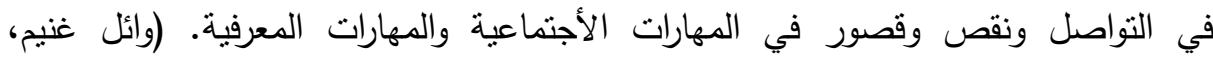

يعد إصابة الطفل بهذا الاضطراب بداية لسلسة من الضغوط النفسية لاى الوالدين بصفة عامة ولاى الأمهات بصفة خاصة، وهذا ما تثير اليه نتائج العديد من الدراسات السابقة. متل لكانل

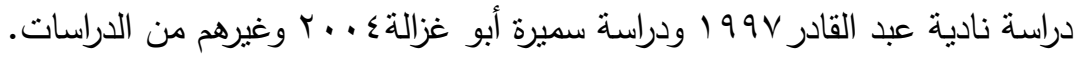

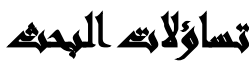

1-ما أنواع الضغوط النى تعانى منها أمهات الاطفال الذاتويين؟

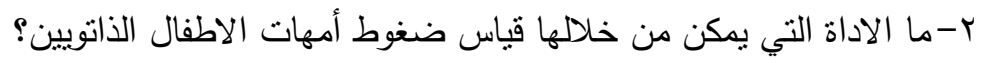

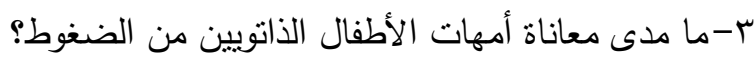

\section{الالهمهية}

1. إن توفير أداة قياسية من الممكن أن يفيد العاملين فى مجال ذوى القدرات الخاصة

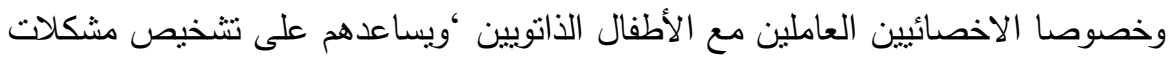

$$
\text { وضغوط الأمهات. }
$$

r. كما أن تثخيص المشكلات يعد خطوة أولى نحو العلاج والتتمية، حيث يمكن الاستعانة

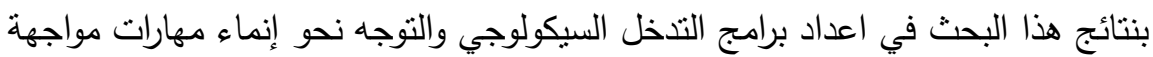

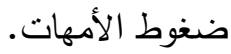




\section{الأهماهيه \\ ا-الكثف عن أنواع الضغوط التى تعاني منها أمهات الأطفال الذاتوبين. r- اعداد مقياس الضغوط أمهات الأطفال الذاتويين.}

\section{=راسايت ساوبر}

أولاً: دراسات تناولت قياس الضغوط لاى أمهات الأطفال الذاتويين:

أجرى وائل غنيم دراسة سنة 10 . بهدف التعرف على الضغوط وأساليب مواجهتها

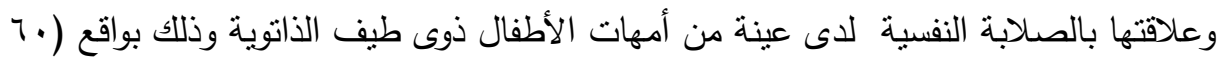

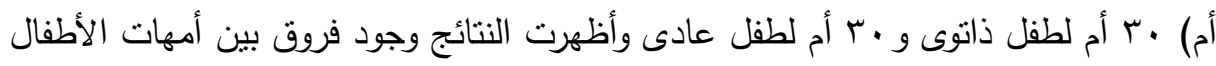
العاديين وأمهات الذاتوبين بالنسبة للضغوط النفسية والتفاعل السلبى على مقياس أساليب

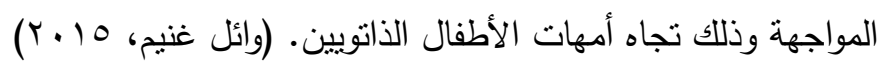
كما قامت ديورات سنة هـ ـ ب بدراسة وصفية بهدف دراسة العوامل المرنبطة بالإجهاد لاى أمهات الأطفال الذاتوبين وذلك بهدف الكثف عن مستوى ضغوطهن، تكونت عينة الدراسة من اب أم لطفل ذاتوى وتمنتلت الأدوات فى مقياس ضغوط الأمهات، وأظهرت النتائج

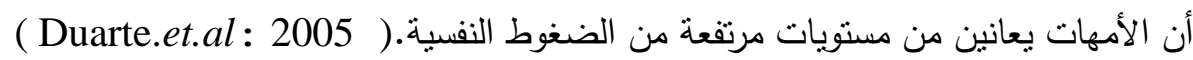
ثانياً: دراسات تناولت قياس المشكلات المعرفية للأطفال الأتويين:

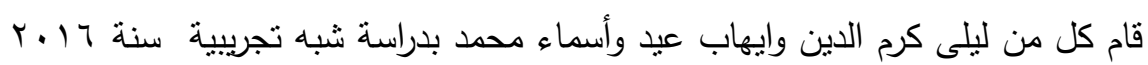

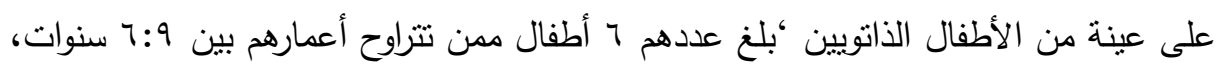

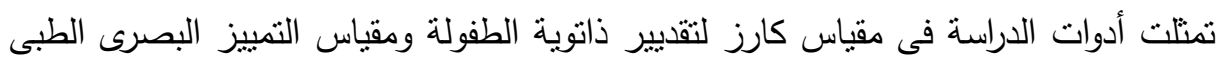
،و قد كثفت النتائج عن وجود فروق ذات دلالة احصائية بين منوسط رتب درجات الأطفال

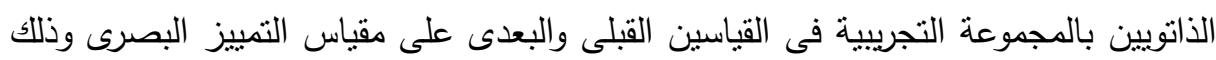

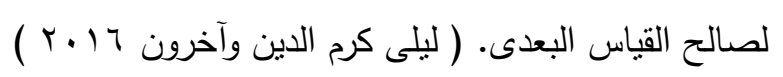
كما أجرتا هيلين وسوليفان دراسة وصفية على عينة من الاطفال الذاتوبين والبالغ عددهم

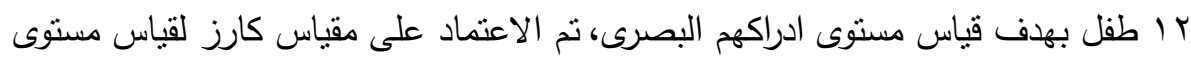
الذانوية وكذلك نم الاعتماد على الدليل التشخيصى الاحصائى الثالث واختيرت العينة من أحد التد 
المراكز التابعة لجامعة واشنطن المختصة بعلاج الاضطرابات الارتقائية ‘أظهرت النتائج أن

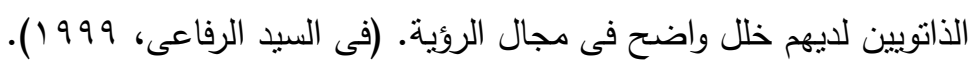

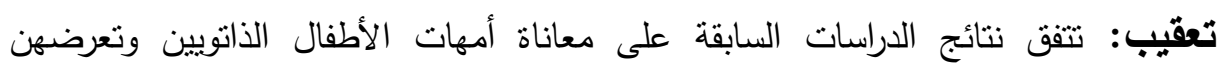

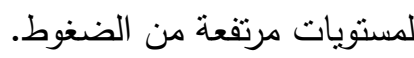
ونثير نتائج الدراسات السابقة أيضا إلى انسام الأطفال الذانويين بنقص مستوى القدرات العقلية ولا سيما التصور والادراك البصرى.

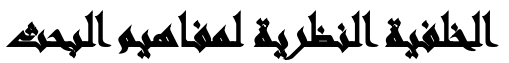

تعريف الضغوط: نعرف الضغوط بأنها نلك الظروف المرتبطة بالقلق والتوتر والثندة وهي

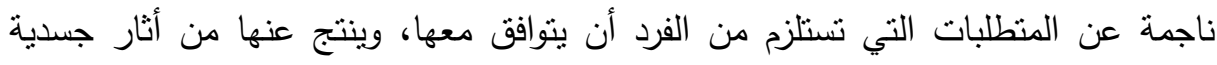

$$
\text { ونفسية (فاروق عثمان، (... (Y). }
$$

كما نعرف بأنها حالة داخلية لادي الفرد بشعر بها تجاه حدث خارجي أو نتيجة تناعل

الفرد مع البيئة الخارجية (Serapemil, 2003).

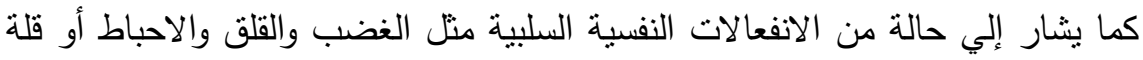

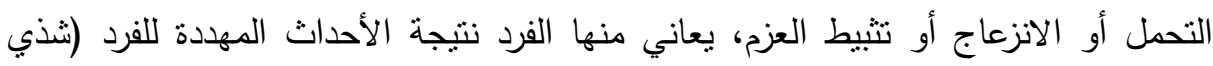

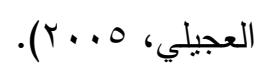

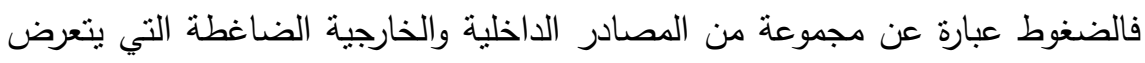

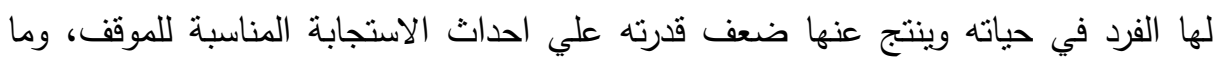

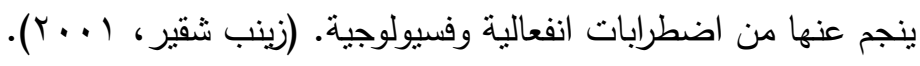

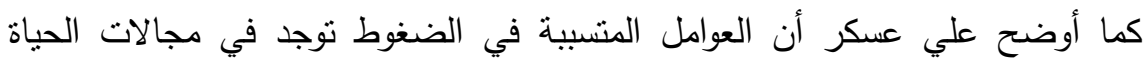

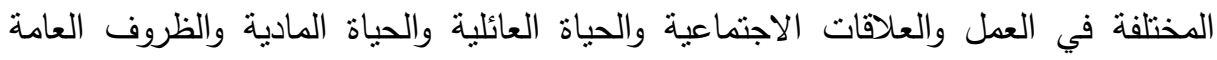

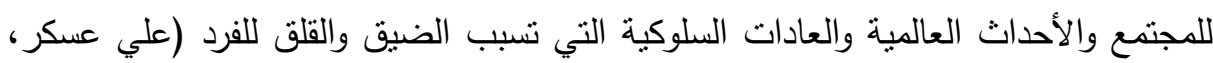




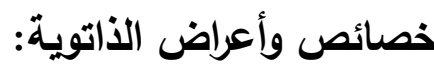

1- العجز الجسمي الظاهري، فقد يتحرك شخص ما أمام الطفل بشكل مباشر ويبتسم له

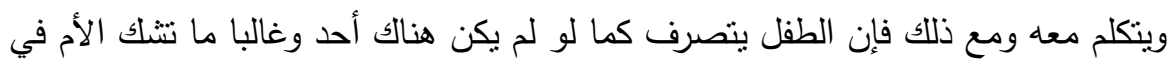

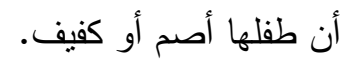

r- البرود العاطفي الثديد، حيث عدم الاستجابة لمحاولة (الحب والعناق أو إظهار مشاعر

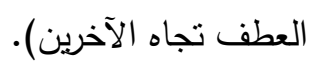

r- الآثار الذاتية، والقيام بسلوكيات نمطية مثل الاهتزاز إلي الأمام وإلي الخلف أثناء الجلوس أو الدوران حول النفس والهمهمة وترديد الكلام لفترة طويلة.

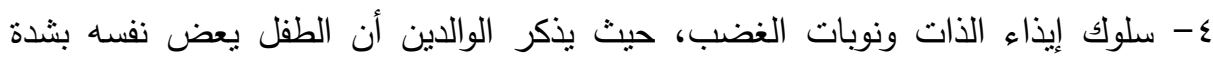

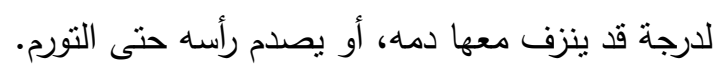

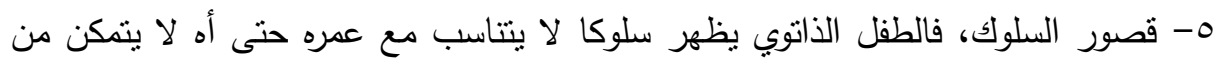

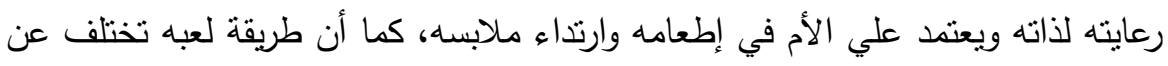

$$
\text { طريقة لعب الآخرين فنراه يضع الألعاب في فمه. }
$$

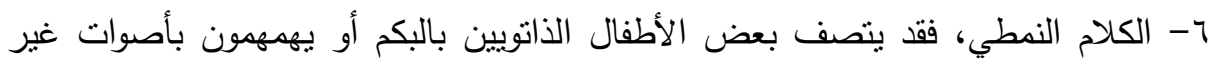

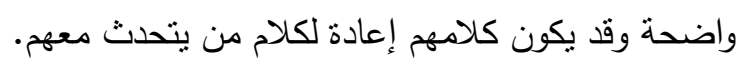

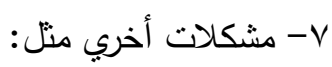

أ- مشكلات ادراكية حيث تدني نسبة الذكاء ومن ثم بصعب علي الطفل القيام بالعمليات

العقلية مثل التفكير والتعرف والادراك والتفكير .

$$
\text { د- ج- نقص القدرة علي الاستجابة. }
$$

هـ - مشكلات الطعام والثراب وعدم الإحساس بالثبع والنمطية في نتاول الطعام واستخدام

$$
\text { نفس الأدوات لأغراض متعددة. }
$$

و - مشكلات نتعلق بعدم ادراك الخطر وعبور الثنارع أثناء سير السيارات (في محمود

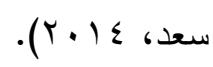




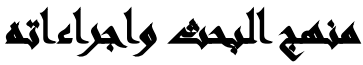

منهج البحث: نم الاعتماد على المنج الوصفى حيث وصف ضغوط الأمهات عينة البحث: تكونت عينة البحث من(اب أنتى) من أمهات الأطفال الذاتويين اللاتى تتراوح

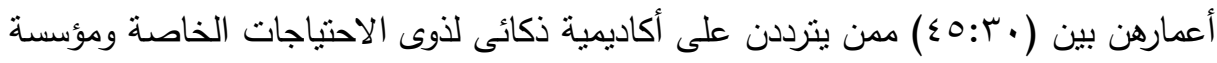
الدكتورة سعاد كفافى للرعاية المتكاملة. الأدوات: تمنلت أدوات البحث فى مقياس ضغوط أمهات الأطفال الذاتويين اعداد/ الباحث وفيما يلى وصف المقياس والاجراءات المتبعة لإعداده: أولاً: الاطلاع علي الاطار النظري وتحليل المفاهيم الخاصة بالضغوط وتقنيد أنواعها كما أخذ في الاعتبار أعراض ومظاهر الذاتويين لأنها السبب الرئيسي وراء شعور الأمهات بالضغوط. تم الاستفادة من الاطار النظري علي النحو التالي: 1- 1- تتاول مفاهيم وتعريفات الضغوط. r- تحليل مصادر وأنواع الضغوط. r- تقنيد الآثار الناجمة عن الضغوط. ع - خصائص وأعراض الذاتوية (كمدر من مصادر ضغوط أمهات الذاتويين). ثانيا: الاطلاع علي المقاييس السابقة للضغوط: منل مقياس أحداث الحياة الضاغطة (إعداد// عماد مصطفي 99 (1) وتمنت هدف المقياس في الحصول علي تقدير كمي لما يدركه الطالب الجامعي من أحداث تمنل ضغط ومشقة عليه وقد تضمن المقياس خمسة مجالات للضغوط ممثلة في الضغوط الاقتصادية، الضغوط المهنية الأكاديمية، والضغوط الصحية وضغوط العلاقات مع الآخرين وضغوط العلاقة مع الأسرة.

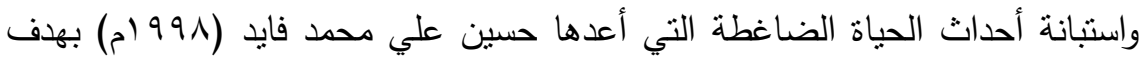
التعرف علي أحداث الحياة الضاغطة التي يواجهها الراشدون وتم تحديد مكونات المقياس في 
ضغوط تتعلق بالمجال الاقتصادي وضغوط تتعلق بالمجال العاطفي والزواجي وضغوط تتعلق

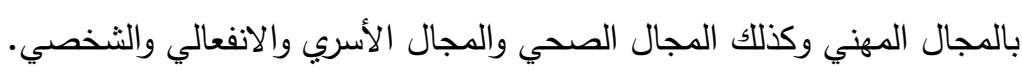

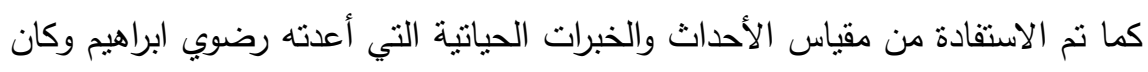
مجموع عدد مفرداته (T) في صورة نساؤلات مفتوحة تدور جميعها حول أحداث الحياة الضاغطة علي المستوي النفسي والاجتماعي والأسري.

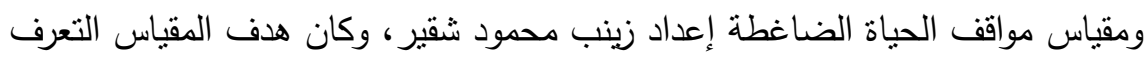

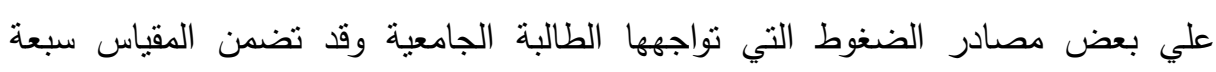
مجالات للضغوط، وهي: الضغوط الأسرية والضغوط الاقتصادية والضغوط الدراسية

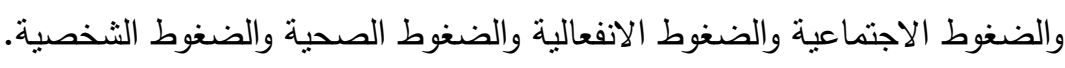

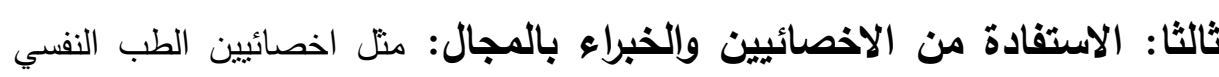

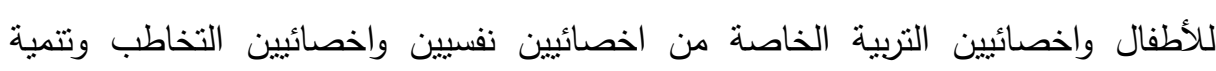
المهارات واخصائيين العلاج الوظائفي وذلك بتطبيق استبانة مفتوحة تتضمن بعض التصنين ونساؤلات علي عينة مكونة من (• (1) من الخبراء بمجال ذوي القدرات الخاصة.

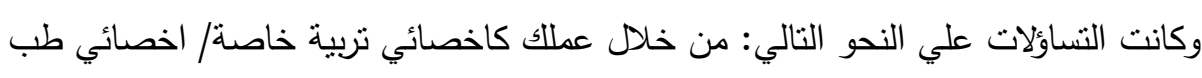
نفسي أطفال ومعرفتلك باضطراب الذاتوية وملاحظتلك لسلوك الطفل ما: أ- ما أهم أعراض الذاتوية؟ ب-وما المشكلات التي تتعرض لها أمهات الأطفال الذاتوبين؟ رابعاً: إجراء استبانة مفتوحة علي أمهات الأطفال الأتويين بواقع ( • 1) أمهات ممن يترددن علي العيادات ومراكز التأهيل المتخصصة في رعاية الأطقال ذوي القدرات الخاصة. 
خامساً: تكوين المفردات: بعد الاطلاع علي التراث النظري السابق من مفاهيم ومصادر للضغوط، والمقاييس السابقة وبعد تحليل مضمون استجابات الخبراء والمتخصصين في مجال الأطفال ذوبي القدرات الخاصة، علي الاستجابات المفتوحة، تم صياغة وتحديد مكونات مقياس

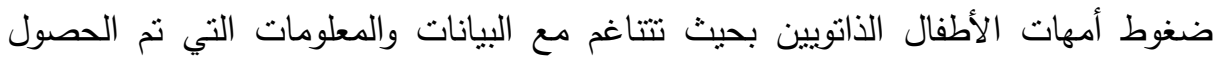
عليها وقد صيغت مكونات المقياس علي النحو التالي: التعريف الاجرائي للضغوط: هي المواقف النفسية والاجتماعية والفسيولوجية والمادية التي تعاني منها أمهات الأطفال الذاتوبين والتي تعيقها عن ممارسة حياتها بشكل طبيعي وتحد من قدرتها علي النوافق ومواجهة الأحداث المختلفة.

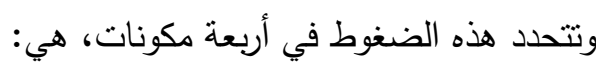
1- الضغوط النفسية، تتمنل في شعور الأم بالقلق والاكتئاب والضيق تجاه حالة الطفل من من حيث انخفاض مستوي قدراته العقلية ومهاراته الاكاديمية والاجتماعية وسوء سلوكه. r- الضغوط الاجتماعية، المشكلات التي تعاني منها الأمهات والتي تتمنل في عدم مشاركة الزوج وعدم تعاونه وعدم مساندة الأهل والأقارب ونظرة المجتمع السلبية لاضطراب الذاتوية

$$
\text { وعدم تعاطف الاخرين أو تفهمهم لأعراض الاضطراب. }
$$

r- الضغوط الفسيولوجية، مجموعة الأعراض الجسمية المصاحبة للشعور بالقلق والتوتر لاصني

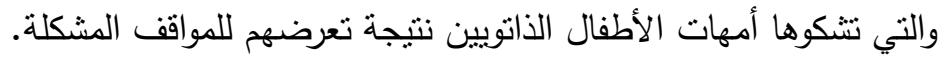

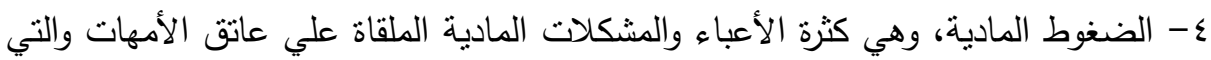
تظهر من خلال ارتفاع نفقات العلاج والرعاية والتأهيل بالاضافة إلي تكاليف المعيشة. سادساً: صياغة البنود: نم صياغة بنود المقياس وفقا للتعريفات الاجرائية لمكوناته، حيث روعي في صياغتها أن تكون مشتقة من التعريف الاجرائي، وأن يتم ترتيبها من الأسهل أو الأبسط إلي الأكثر تعقيداً.

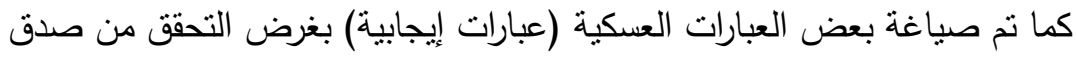
استجابات الأمهات علي المقياس. 
سابعا: تحديا بدائل الاستجابة وتصحيح المقياس: تم تحديد بدائل الاستجابة

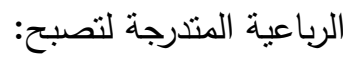
كثيرا (乏)
أحيانا (r)
نادرا (r)
(أبدا (1)

ويتم تصحيح العبارات العكسية بالعكس.

ثامنا: تحكيم المقياس: تم عرض المقياس في صورته المبدئية علي عدد من المتخصصين في المجال من أساتذة علم النفس وأطباء الأطفال واخصائيين التربية الخاصة وذللك بواقع (• () خبراء للاستفادة من وجهة نظرهم فيما يتعلق بمكونات المقياس ومدي التي

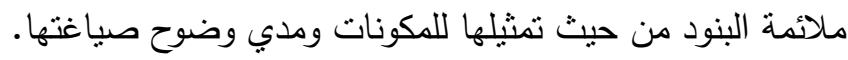
وبناء علي آراء السادة المحكمين تم تعديل بعض العبارات ونم حذف البعض منها،

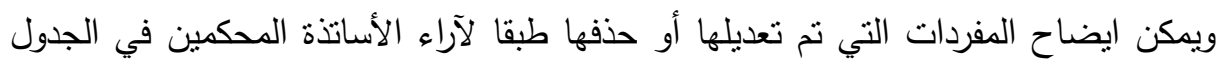
التالي:

\begin{tabular}{|c|c|c|c|}
\hline السبب & العبارة بعد التعديل & العبارة قبل التعديل & المكون \\
\hline مكررة & حذفت حت & 1 - أخشي علي مدي ابني من له & النفسي \\
\hline مكررة - مكرة & حذفت & 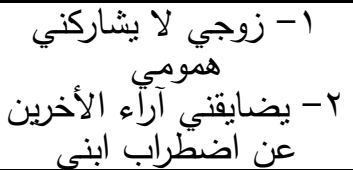 & الاجتماعي \\
\hline صياغة & أنخفاض ضنغ بارتفاع| الدم & 1- ضغط دمى مرتقع & فسيولوجي \\
\hline صياغة & تدبير أعَوالى المنادية & لا آتمكن من تدبير أحوالي & المادي \\
\hline
\end{tabular}

تاسعا: حساب الكفاءة السيكومتريةة: تم تطبيق المقياس علي عينة من أمهات الأطفال الذاتوبين وذلك بواقع (آr) أم بهدف التحقق من كفاءة المقياس وحساب الصدق والثبات والاتساق الداخلى ودنى 
أولا :حساب صدق المقياس: نم التحقق من صدق المقياس من خلال الطرق التالية:

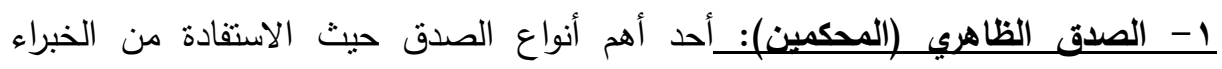

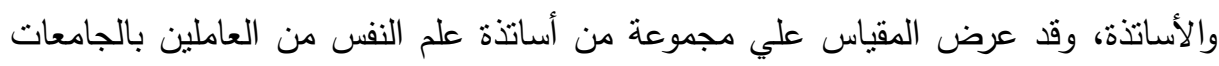

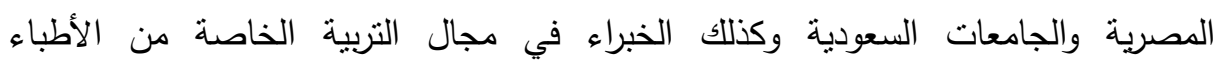
والاخصائيين العاملين بمراكز رعاية وتأهيل الأطفال ذوي القدرات الخاصة وقد تم الاستفادة

من أراء المحكمين وأخذ آرائهم بعين الاعتبار من حذف عبارات مكررة أو تعديل الصياغة.

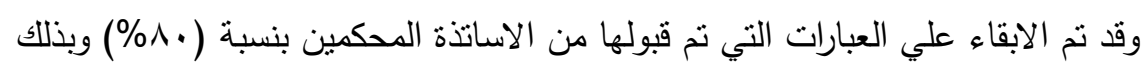
يعتبر المقياس صادقاً من الناحية الظاهرية أو من وجهة نظر الماركات المحكمين.

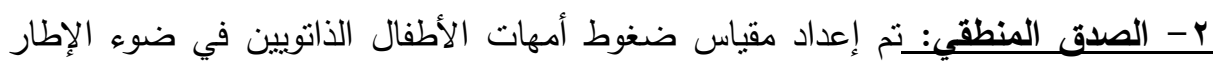
النظري وما ورد من تعريفات ومصادر وعواقب للضغوط وكذللك في ضوء استعراض الملامح

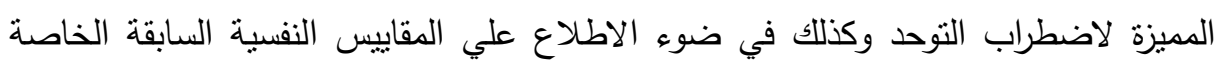
بالضغوط والخاصة بتتخيص الذاتوية ومن ثم يعد المقياس صادقا من الناحية المنطقية لأنه يمثل الظاهرة التي يقيسها والتي تعد من أجلها. ثانياً:حساب ثبات المقياس: نم التحقق من ثبات المقياس من خلال حساب معاب معامل ألفا

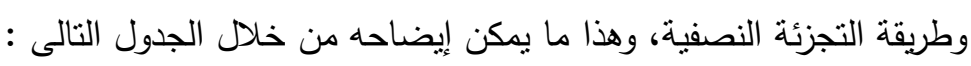
جدول (r): معامل ثبات مقياس ضغوط أمهات الأطفال الذاتويين بطريقتى ألفا كرونباخ والتجزئة النصفية

\begin{tabular}{|c|c|c|}
\hline \multicolumn{3}{|c|}{ ن" ا "ا"من أمهات الأطفال الذاتويين } \\
\hline ثبات التجزئة النصفية & معامل آلفا كرونباخ & طرق الثبات \\
\hline$\cdot, \vee \vee 99$ & $\cdot, \vee \cdot q$ & معامل الثبات \\
\hline
\end{tabular}

وبمراجعة معاملات الثبات الواردة فى الجدول السابق أتضح أن مقياس ضغوط أمهات

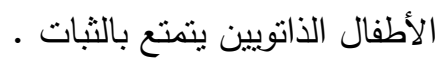
ثالثا :الإتساق الداخلى: نم حساب الاتساق الداخلى للمقياس من خلادل معامل الارتباط بين الدرجة الكلية للمقياس وبين درجة كل مكون من مكوناته الفرعية. 
وكذللك حساب معامل الارتباط بين الارجة الكلية لكل مكون فرعى وبين درجة كل مفردة من المفردات التى تتنمى لهذا المكون، ويوضح الجدول التالى الارتباط بين الدرجة الكلية للمقياس وبين درجة كل مكون من مكوناته الفرعية

جدول (r): ارتباط الدرجة الكلية للمقياس بدرجة كل مكون من مكوناته الفرعية:

\begin{tabular}{|c|c|}
\hline معامل الإرتباط & المكون \\
\hline$\cdot, \Gamma \wedge \Gamma$ & الضغوط النفسية \\
\hline$\cdot, \wedge \neg \wedge$ & الضغوط الإجتماعية \\
\hline$\cdot, \varepsilon \cdot 7$ & الضغوط الفسيولوجية \\
\hline$\cdot, 09 Y$ & الضغوط المادية \\
\hline
\end{tabular}

وبمراجعة قيم (ر) الواردة فى الجدول السابق أتضح أن أعلى قيمة كانت لارثباط

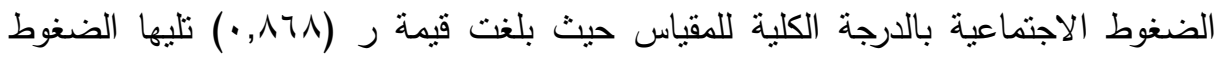

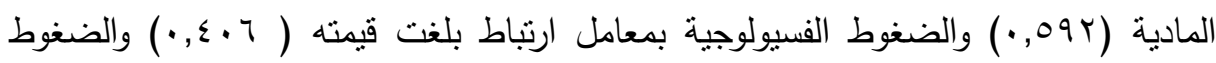

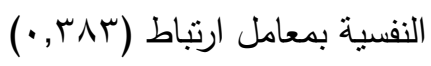

وبعد التحقق من الكفاءة السيكومترية للمقياس أصبحت الصورة النهائية لمقياس ضغوط أمهات الأطفال الذاتوبين على النحو التالى: وصف المقياس: ينكون المقياس من (0؛) عبارة، وأعلى درجة من الممكن أن يحصل عليها

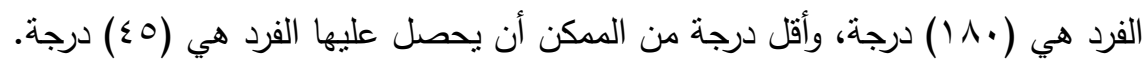

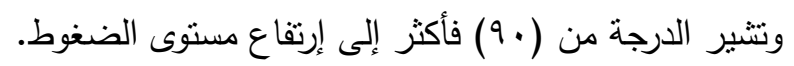

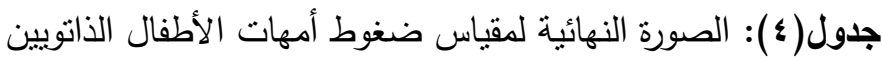

\begin{tabular}{|c|c|}
\hline 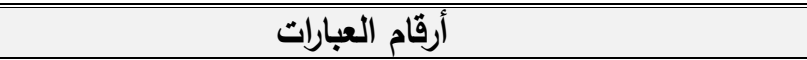 & المكون \\
\hline$\varepsilon r-\varepsilon 1-r V-r r-Y q-r 0-r|-| V-1 r-9-0-1$ & الضغوط النفسية \\
\hline 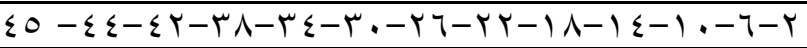 & الضغوط الإجتماعبة \\
\hline$r q-r 0-r 1-r V-r r-19-10-11-V-r$ & الضغوط الفسيولوجية \\
\hline$\Sigma \cdot-r \neg-Y Y-Y \wedge-Y \xi-Y \cdot-17-1 Y-\lambda-\varepsilon$ & الضغوط المادية \\
\hline
\end{tabular}


نتائج البحث: للتحقق من صحة هذا الفرض تم استخدام الاسلوب الإحصائي الوصفي لحساب

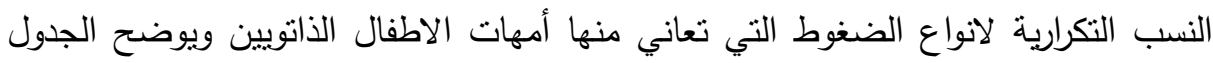
التالي قيم المتوسطات والانحرفات المعيارية للضغوط.

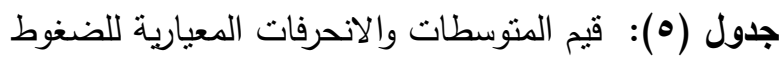

\begin{tabular}{|c|c|c|}
\hline الانحراف & المتوسط & أنواع الضغوط \\
\hline$r, \tau$ & $r \cdot, \leqslant q$ & النفسية \\
\hline 9,9 & $1 \wedge, \vee 9$ & الاجتماعبة \\
\hline 0,0 & 10,01 & المادية \\
\hline$\varepsilon, \wedge$ & 17,00 & الجسدية \\
\hline
\end{tabular}

ومن خلال القيم الواردة في الجدول السابق يتضح أن أكثر أنواع الضغوط شيوعاً لاى

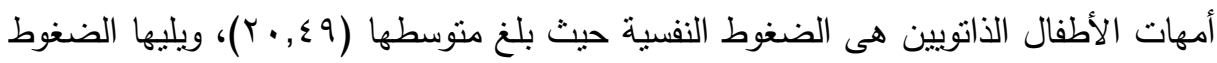

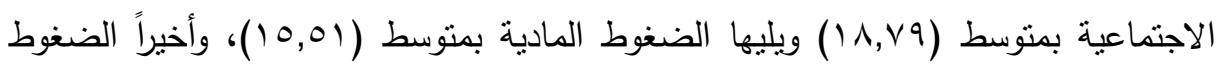
الجسدية بمتوسط (0. (7 1 ()).

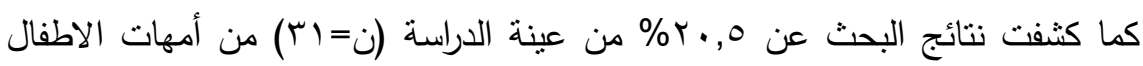

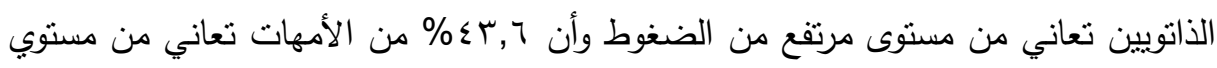

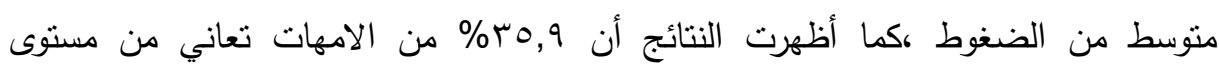
منخفض من الضغوط. وتتفق نتيجة هذا البحث مع النتائج التى أسفرث عنها دراسة نادية عبد القادر والتى توصلت الى وجود علاقة أرتباطية داله بين اضطراب الذانوية ومعاناة الأمهات من الضغوط لئه

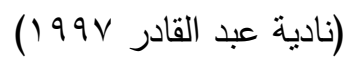
وتؤكد نتائج دراسة " DUARTE" على هذه النتيجة أن امهات الاطفال الذاتوبين تعاني من مستويات مرتفعة من الضغوط. ( Duarte.et.al: 2005 ) 


\section{المتهوياهي}

من خلال عملي كاختصاصي نفسى في مجال ذوى الاحتياجات الخاصة ومن خلال تجربتي بتطبيق هذا البحث،لاحظت الاحتباج الثديد( لعينة البحث من الأمهات وكذللك داصني

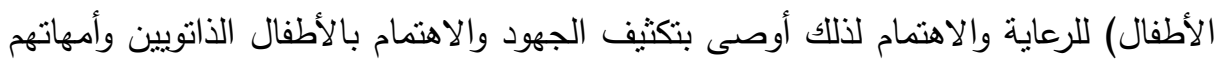
والبحث عن أحدث البرامج العلاجية وإستراتيجيات التأهيل بهدف الإرتقاء بقدراتهم العقلية وإنماء مهاراتهم الاجتماعية والتفاعل مع الأخرين، بغرض الارتقاء بقدراتهم وتخفيف العناء عن

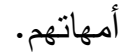

\section{Ind Ang}

ا. فعالية برنامج لإنماء مهارات التواصل اللفظى وغير اللفظى للأطفال الذاتوبين. r. فعالية برنامج لإنماء مهارات التفاعل الإجتماعى لدى الأطفال الذاتوبين.

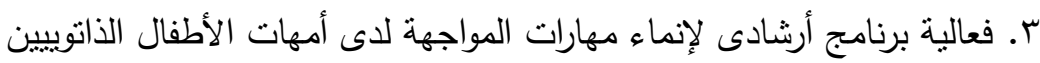

\section{المرالئم}

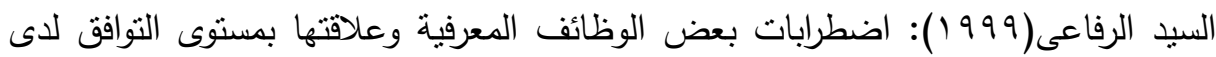

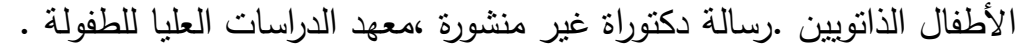

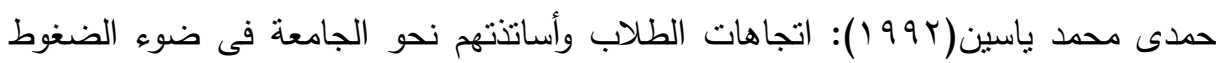
النفسية - رؤية سيكومترية تحليلية ـ مؤتمر كلية التربية، القاهرة .

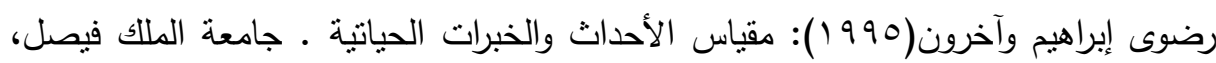
كلية الطب والعلوم الطبية، العيادة النفسية السلوكية .

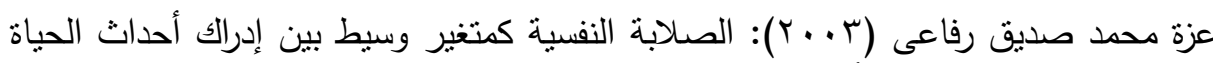

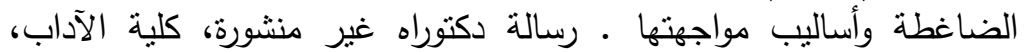

جامعة حلوان

على عسكر (991 (1): ضغوط الحياة وأساليب مواجتها .القاهرة .دار الكتاب الحديث . فاروق السيد عثمان( ( . †): القلق وادارة الضغوط النفسية ،القاهرة .مكتبة الأنجلو المصرية. 


$$
\begin{aligned}
& \text { ليلى كرم الدين، ايهاب عيد، أسماء محمد: فاعلية برنامج لنتمية التمييز البصرى لدى الأطفال }
\end{aligned}
$$

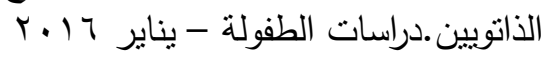

$$
\begin{aligned}
& \text { نادية عبد القادر (1997 ): الاضطراب التوحدى لدى الأطفال وعلاقته بالضغوط الوالدية رسالة } \\
& \text { ماجستير غير منشورة، معهد الطفولة جامعة عين شمس الابس } \\
& \text { محمد صبرى وهبة: الأطفال ذو التوحد واضطراب الدمج الحسى، تربية الأطفال ذوى القدرات }
\end{aligned}
$$

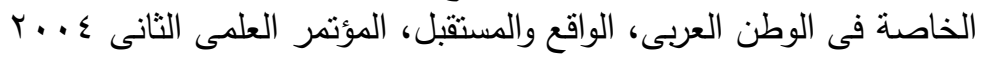

Autism a society of American (2003).information came from the net .http/:www.autismsociety.org/.

Duarte,c.bordin,I,12005 factors associatied with stress in mothers of children with autism,sage publication and national autistic society,9(4)416-427

Mason ,misy,a.(2005)effects of therapeutic riding in children with autism .dissertation abstracts international.vol56-12a capplla university

volkmar,f. and cohen,d(1991).non autistic pervasive developmental disorder .psychiatry,lipp in cott company phiiladelphia,london revised edition 
أحمد فرج عبد الباقي محمد وآخرون

\title{
THE STRESS OF MOTHERS OF AUTISTIC CHILDREN
}

\author{
Ahmed F. A. Mohammed ${ }^{(1)}$; Gamal Sh. Ahmed ${ }^{(2)}$ \\ and Ouda G. Mohammed ${ }^{(2)}$ \\ 1) Soad Kafafy Establishment for Caring, MUST University 2) Faculty \\ of Postgraduate Childhood Studies, Ain Shams University
}

\begin{abstract}
This research aimed to assmment the stress of mothers of autistic child. the sample selected of( 31) mother of autistic child who frequented the clinics and centers of care and rehabilitation. There ages were from (30 to 45) the research was depending on descriptive method and the tools $\mathrm{w}$ ere mothers stress scale. The results have showed that, mothers of autistic child were suffered from psychological stress, social stress, physiological stress, and Economic stress.
\end{abstract}

